\title{
Power of Detection and Accuracy in Elemental Trace Analysis
}

\author{
G. ToLG**** and P. TSCHOPEL ${ }^{* *}$ \\ *Institut für Spektrochemie und Angewandte Spektroskopie, \\ Bunsen-Kirchhoff-Str. 11, D-4600 Dortmund 1, F.R.G. \\ **Max-Planck-Institut für Metallforschung, Laboratorium für Reinststoffanalytik, \\ Bunsen-Kirchhoff-Str. 13, D-4600 Dortmund 1, F.R.G.
}

\begin{abstract}
Today, there exists a demand for analytical methods and procedures with absolute power of detection down to the pg-range for numerous elements in complex matrices. They should enable either to detect very low element concentrations in bulk samples or to acquire exact data on elemental distributions on the micro scale. With decreasing absolute amounts to be determined in real samples, detectability and reliability are in increasing discrepancy with the consequence that analytical results become unreliable or wrong and thus very often particularly uneconomic. The fast evaluation of analysis results for lower and lower concentrations or amounts to be determined is limited by a rapid increase of systematic errors of a physical, but predominantly of a chemical nature. In the attempt, for instance, to properly derive concentrations from intensities, great difficulties are often encountered. This basic problem occurs at the ng-level and still far more for analyses at the pg-level. The solution of this analytical problem is not a general one but is obtained by special strategies in each individual case. In problem-orientated work involving extreme trace analyses, the reliability and economy of a procedure will therefore remain incalculable until it will be possible to recognize and eliminate the sources of systematic errors and to confirm the analytical results by independent procedures. The strategies leading to the best results for elemental determinations at $\mathrm{ng}$ - and pg-levels will be generally discussed and demonstrated by examples of the determination of $\mathrm{Hg}, \mathrm{Se}, \mathrm{Tl}$ and precious metals.
\end{abstract}

Keywords Extreme trace analysis, accuracy, systematic error, contamination, mercury, selenium, thallium, platinum

\section{General Section}

In analytical research, the prime aim is to improve the methodological figures of merit, such as power of detection, reliability and economic aspects - in order to supply analytical methods for the interdisciplinary demand of today and tomorrow. ${ }^{1-4}$

The improvement of the power of detection for the elements and their species, and this not so much with regard to bulk analysis, but far more so with regard to micro-distribution analysis 5,6 is the central point of these innovative endeavors. In this connection, the determination of very small absolute amounts is particularly important.

It becomes impressively evident by evaluations of the numerous interlaboratory comparative analysis ${ }^{7-10}$ that, mainly due to systematic errors, a combination between highest power of detection and high reliability of results in a procedure is difficult to generalize; too many parameters, such as the element, its determinable concentration or absolute amount, the method involv- ed, but chiefly the matrix and its composition, prohibit any unambiguous correlations. Only the general statement can be made that with decreasing absolute amounts to be determined, systematic errors increase dramatically and, accordingly, they are the main problem in extreme trace analysis. ${ }^{11-13}$

This can best be shown by the gradual change in the data of the literature concerning the normal concentrations of some trace elements in human blood or serum. ${ }^{1,14}$ Blood serum is a frequently analyzed and an over a lengthy period of time relatively uniform matrix, whose normal contents of trace elements are mainly constant (biological range). The improvement of accuracies of analytical methods becomes obvious from a long-time observation of the literature. The normal contents of some selected trace elements, which were found by different authors in two periods before and after 1976 are listed in Fig. 1.

Two categories of trace elements can be distinguished:

1. Elements for which similar values are found in both periods. These are e.g. $\mathrm{Cu}, \mathrm{Zn}$ and - to a some 


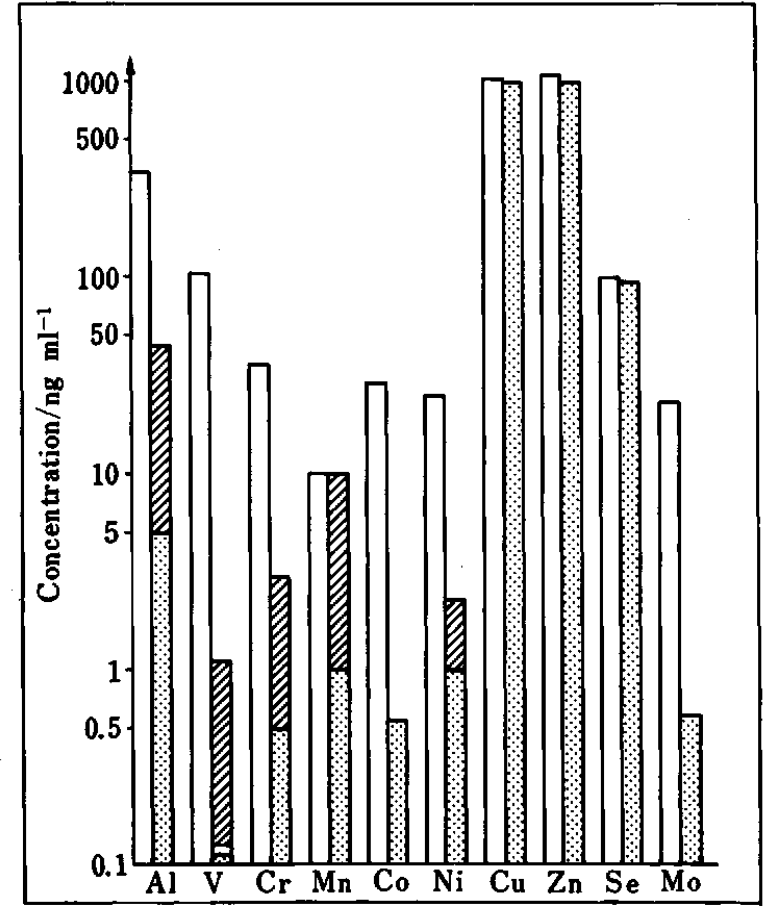

Fig. 1 Comparison of the mean values of several elements in blood serum as stated in the literature; $\square$, determined prior to $1976 ; 10$, after $1976 ; 0$, realistic (according to a compilation by Versieck and Cornelis. ${ }^{14}$

lesser extent - also Se. The reliable determination of these elements does no longer impose any difficulty in principle and with very few exceptions this statement can also be made for their determination in other biotic matrices, provided the concentrations are in the same order of magnitude or higher. In these cases it would make sense to work out standard procedures for routine analyses.

2. For elements occurring in very low concentrations, such as $\mathrm{Al}, \mathrm{V}, \mathrm{Cr}$, greatly differring results are found. Here there obviously still exist sources for grave systematic errors, of which the elimination or reduction requires further trace analytical experience and a good deal of critical capability of the analyst.

The problems occurring with the elements of the second category shall be demonstrated again by a specially impressive case which we were confronted with 15 years ago. ${ }^{2}$ In an interlaboratory comparison of the determination of $\mathrm{Hg}$ in milk powder ( $c f$. Table 1) it was found that not the statistical mean value of all analysis results, but the lowest value found proved to be nearest to the true value. At that time, most of the determination procedures used for $\mathrm{Hg}$ were hampered by grave systematic errors. A normal error distribution did not exist, so that a statistical evaluation of results was not allowed. This situation has changed today due to a learning process over many years, and became less drastic with respect to $\mathrm{Hg}$ analysis. However, for many other problematic
Table 1 Results of a $\mathbf{H g}$-interlaboratory analysis on milk powder from the year 1973. ${ }^{2}$

\begin{tabular}{cccc}
\hline $\begin{array}{c}\text { Mean value of } \\
\text { the laboratories, } \\
\text { ppb }\end{array}$ & $\begin{array}{c}\text { Total mean } \\
\text { value, } \\
\text { ppb }\end{array}$ & SD,ppb & RSD, \% \\
\hline 10 & & & \\
1 & & & \\
100 & & & \\
8 & 35.5 & 44 & \\
\hline 0.5 & & & \\
10 & & & \\
44 & & \\
1.4 & & \\
50 & & \\
11 & & \\
136 & & \\
54 & & \\
\hline
\end{tabular}

The lowest value proved closest to the true value.

elements it still remains bad with regard to bulk analysis. An additional drawback in some cases is the fact that no methods with sufficient power of detection are available.

It should be emphasized that many elements, assumed to be "problem-free" today may become "problematic" again when one has to determine their microdistribution, for instance, in tissue compartments, in protein fractions of the blood serum, in body cells or even in macromolecules which would include the determination of even smaller absolute amounts. Quite similar is the situation in other fields of analysis, e.g. in materials sciences or semiconductor techniques.

The power of detection required in these cases often must be at the pg-level and consequently, the question of systematic errors, their origin, their recognition and elimination, becomes the question of central interest again for practically all elements.

Another fact has to be taken into consideration: Correct results have a decisive influence on the economy of an analytical procedure. Wrong data and especially consequences resulting from low-cost and uncritical methodological simplifications may ultimately be very expensive. Only the optimum strategy leads to correct results and thus to economic utility. The following statements may be helpful in finding out the right way.

1. All direct instrumental methods, which are used in routine analysis because of economic reasons, have to be calibrated. But calibration causes great difficulties, excepted for a very few cases such as in activation analysis. In most methods widely varying elemental cross interferences due to matrix or concomitant elements are encountered. So, as long as no confirmed mathematical functions between signal intensities and element concentrations exist, one has to refer to reliable standard reference materials; however, these standards do not exist for the $\mathrm{ng} / \mathrm{g}$-region and none at 
all for the pg/g-region.

Therefore, a solution technique with the standard addition method is often the method of choice in order to compensate for matrix effects during calibration. But frequently, no attention is paid to the fact that this possibility is only then free from systematic error, when the calibration function over the entire concentration range is linear, the background level is known, and if the sensitivity for the element present in the sample solution agrees with that of the element added. ${ }^{3}$ The latter condition will only be fulfilled, when the bonding characteristic of the element in the sample is identical with that of the element in the standard solution. Figure 2 illustrates the problem by the Tl-determination in a urine specimen using AAS. From timeresolved spectra it can be observed that the added Tldose shows a different vaporization behavior to that of the sample-inherent $\mathrm{Tl}$, due to the difference in the bonding characteristics. ${ }^{15}$ With standard addition the systematic errors grow with the increase in the complexity of the sample. The most favorable working conditions exist, if the sample only is a pure solution of the elements with defined bonding characteristics.

2 . In order to achieve optimal power of detection and reliability the elements should be isolated on a smallest
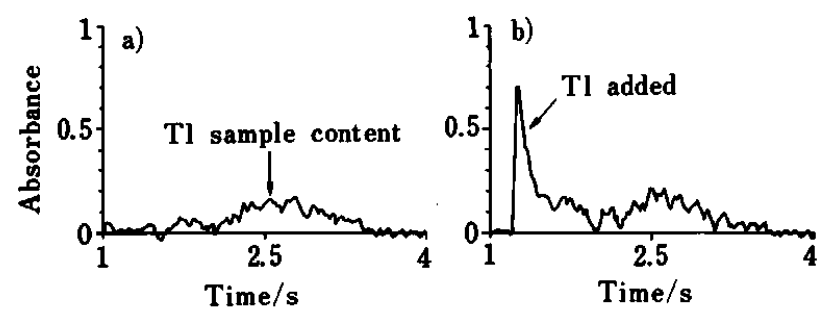

Fig. 2 Time-resolved spectra obtained during an AASdetermination of $\mathrm{Tl}$ in urine. ${ }^{15}$ Atomization temperature: $1300^{\circ} \mathrm{C}$, ramp time: 0 . a) sample-inherent $\mathrm{Tl}$ content, b) sample spiked with $20 \mathrm{ng} / \mathrm{ml} \mathrm{Tl}$. possible target area or into a minimum volume. Then matrix effects can be eliminated to a great extent; the concentration results in higher analytical signals, however, only when chemical operatioins are carried out on micro-scale ( $\mu \mathrm{l}, \mathrm{mg}$ ). Therefore, many manipulations can be carried out far simpler, faster and safer on micro-scale which means a further reduction of possible systematic errors.

3. The reproducibility of the results of a method gives no information about its accuracy. In extreme trace analysis, the accuracy of a result can only be confirmed by the use of two or more methods, which base on fully independent principles. This means, that they have to differ in each analytical step such as sample preparation, decomposition, separation and determination. Therefore, only when different procedures come to the same results, one can assume that systematic errors are absent. A further way of getting confirmation of the accuracy makes use of interlaboratory comparisons.

From conclusions made with respect to points 1 to 3 and various other provisions for analysis in the $\mathrm{ng} / \mathrm{g}$ and $\mathrm{pg} / \mathrm{g}$-range, it follows also that special attention has to be paid to the combined procedures, combining decomposition and separation steps in order to isolate and preconcentrate the elements to be determined with the actual determination. The excess of time and manpower taken up by these procedures is compensated by the fact that combined methods can be simply and reliably calibrated by aqueous standard solutions. Once the question of accuracy of combined procedures is cleared, we may then change to the fast, direct instrumental multielement methods for routine analysis, which use standard materials prepared via combined procedures. Combined procedures can by no means be considered as favorable with respect to systematic errors. We have to expect in particular, blank values caused by contamination in each analytical step, but also elemental losses due to adsorption or volatilization. A rough picture of the

Table 2 Systematic errors and their approximate distribution in a trace analytical combined procedure

\begin{tabular}{|c|c|c|c|c|}
\hline \multirow[b]{3}{*}{$\begin{array}{l}\text { Step of } \\
\text { operation }\end{array}$} & \multicolumn{4}{|c|}{ Type of error } \\
\hline & Contamination & Adsorption & \multirow[t]{2}{*}{ Volatilization } & \multirow{2}{*}{$\begin{array}{l}\text { Cross interferences by elements } \\
\left(\begin{array}{c}\text { chemical reactions, } \\
\text { signal-interferences, } \\
\text {-coincidence, } \\
\text {-background }\end{array}\right)\end{array}$} \\
\hline & $\left(\begin{array}{l}\text { reagents, } \\
\text { tools, } \\
\text { laboratory air }\end{array}\right)$ & $\left(\begin{array}{l}\text { tools, } \\
\text { interfaces }\end{array}\right)$ & & \\
\hline Sampling & +++ & -- & - & \pm \\
\hline Sample preparation & +++ & - & - & \pm \\
\hline Dissolution, decomposition & +++ & - & --- & \pm \\
\hline Separation, preconcentration & ++ & $\ldots-\ldots$ & - & \pm \pm \pm \\
\hline Determination: & + & - & -- & \pm \pm \pm \\
\hline Excitation & & & & \\
\hline Calibration & & & & \\
\hline Evaluation & & & & \\
\hline
\end{tabular}


weak points in the different analytical steps of a combined procedure is given in Table 2.

During the past years, vast experience has been gathered in the difficult recognition and elimination of systematic errors and their causes. This topic has already been referred to frequently in other contexts. ${ }^{11-}$ 13,16 Therefore, it is intended in this contribution to go only briefly into the problem of contamination again, as it might be more important to come to a solution here than to attempts to develop even more sensitive detection systems.

High blank values particularly have to be expected for all elements which commonly occur in the earth

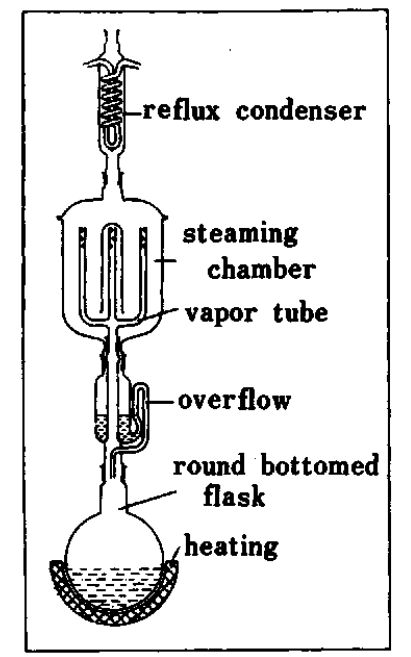

Fig. 3 Equipment for vapor-cleaning in order to reduce contaminations on vessel surfaces. ${ }^{11}$

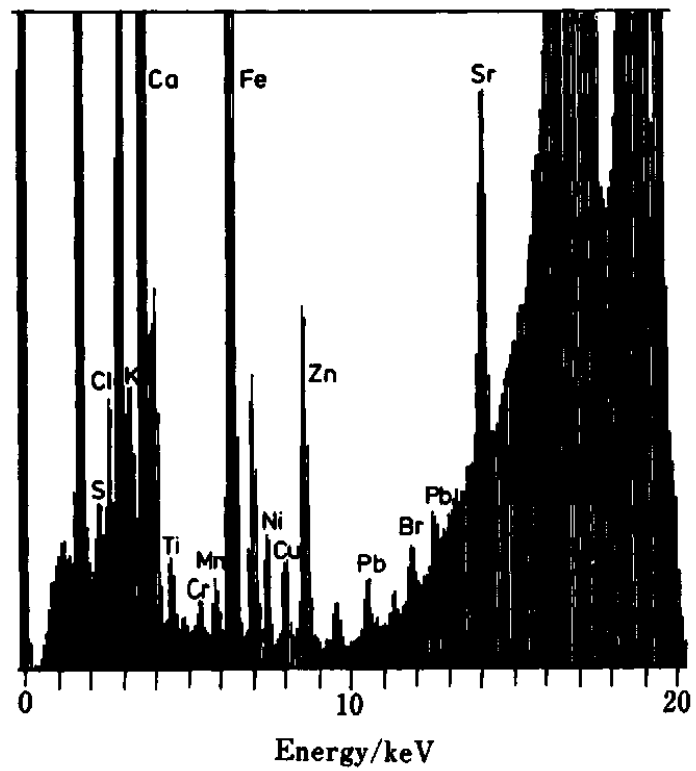

Fig. 4 TRXRF-spectrum ${ }^{17}$ of elemental impurities on an untreated quartz plate. crust such as $\mathrm{O}, \mathrm{Si}, \mathrm{Al}, \mathrm{Fe}, \mathrm{Ca}, \mathrm{Na}, \mathrm{Mg}, \mathrm{K}, \mathrm{Ti}, \mathrm{Mn}, \mathrm{P}$, C. However, considerable risks of contamination are also found for elements such as $\mathrm{B}, \mathrm{Cr}, \mathrm{Ni}, \mathrm{Cu}, \mathrm{Zn}, \mathrm{Hg}$, $\mathrm{Pb}$, which occur in the environment due to anthro-

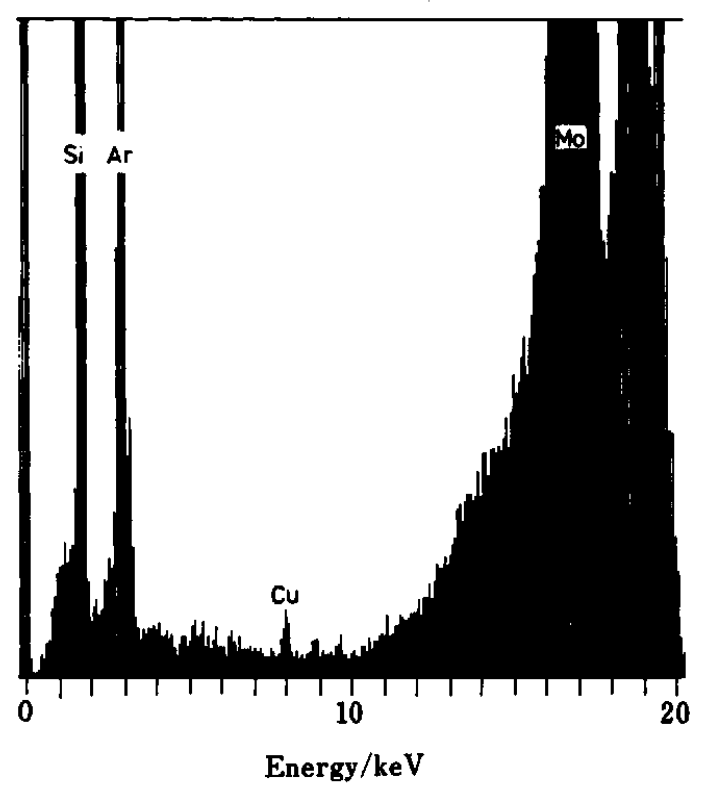

Fig. 5 TRXRF-spectrum ${ }^{17}$ of elemental impurities on the same quartz plate, $c f$. Fig. 4, after vapor-cleaning for several hours.

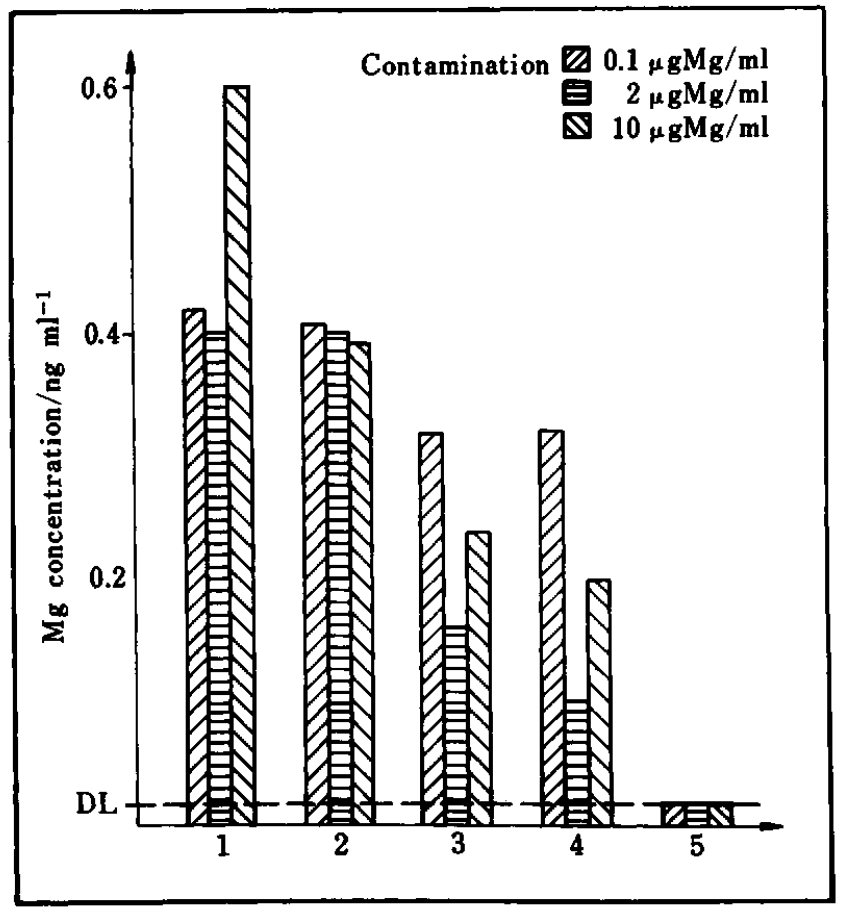

Fig. 6 Mg-contents of water in volumetric flasks $(50 \mathrm{ml}$, Duran) after several different cleaning procedures. ${ }^{11}$ Rinsing: $1,3 \times$ with $0.1 \mathrm{M} \mathrm{HCl} ; 2,7 \times$ with $0.1 \mathrm{M} \mathrm{HCl} ; 3,7 \times$ with $0.1 \mathrm{M} \mathrm{HCl}+8 \times$ with $\mathrm{H}_{2} \mathrm{O} ; 4,7 \times$ with $0.1 \mathrm{M} \mathrm{HCl}+18 \times$ with $\mathrm{H}_{2} \mathrm{O}$; Steaming: 5,2 h with $\mathrm{HNO}_{3}+2$ h with $\mathrm{H}_{2} \mathrm{O}$. 
pogenic activities and technical progress.

Problems start with the choice of a suitable vessel material (e.g. quartz, PTFE, PP, glassy carbon) and with the cleaning of the material surfaces. Most effective cleaning could be realized by treating the vessels with acid- and water-vapor over several hours (Fig. $3^{11}$ ). Figures 4 and 5 show spectra of a contaminated quartz surface before and after vapor cleaning. ${ }^{17}$ For such investigations especially the X-ray fluorescence analysis carried out under excitation conditions of total reflection (TRXRF) is very suitable. ${ }^{18}$ The cleaning effect for $\mathrm{Mg}$ obtained with vapor treatment is compared to that of other cleaning techniques ${ }^{11}$ in Fig. 6.

Further high purity reagents ${ }^{19-22}$ and clean benches and clean rooms ${ }^{12,23-25}$ are of highest importance for the extreme trace analysis. For this point and for the sources of systematic errors during sampling ${ }^{26-28}$ and sample preparation ${ }^{10-13}$, we have to refer to the literature.

Serious systematic errors may also be introduced by the techniques of sample decomposition. This problem cannot be discussed in a generalizing manner, because there exists no universal decomposition method. Several methods are available and their analytical suitability has to be tested from one case to another. ${ }^{16,29-31}$ Where as in principle, there are no longer problems for organic matrices, there are often still considerable difficulties in the dissolution of inorganic matrices, such as oxides, silicates, nitrides, carbides, borides. This is required in the analysis of geological and technical materials (e.g. ceramics, refractory metals and materials) so that it would seem worthwhile to develop new efficient decomposition techniques.

Quite a few good separation methods now are at our disposal; however, also there is still considerable room for improvement. Essentially, one could say that

Table 3 Limits of detection (LD) of the most important determination methods used in trace analyses of the element

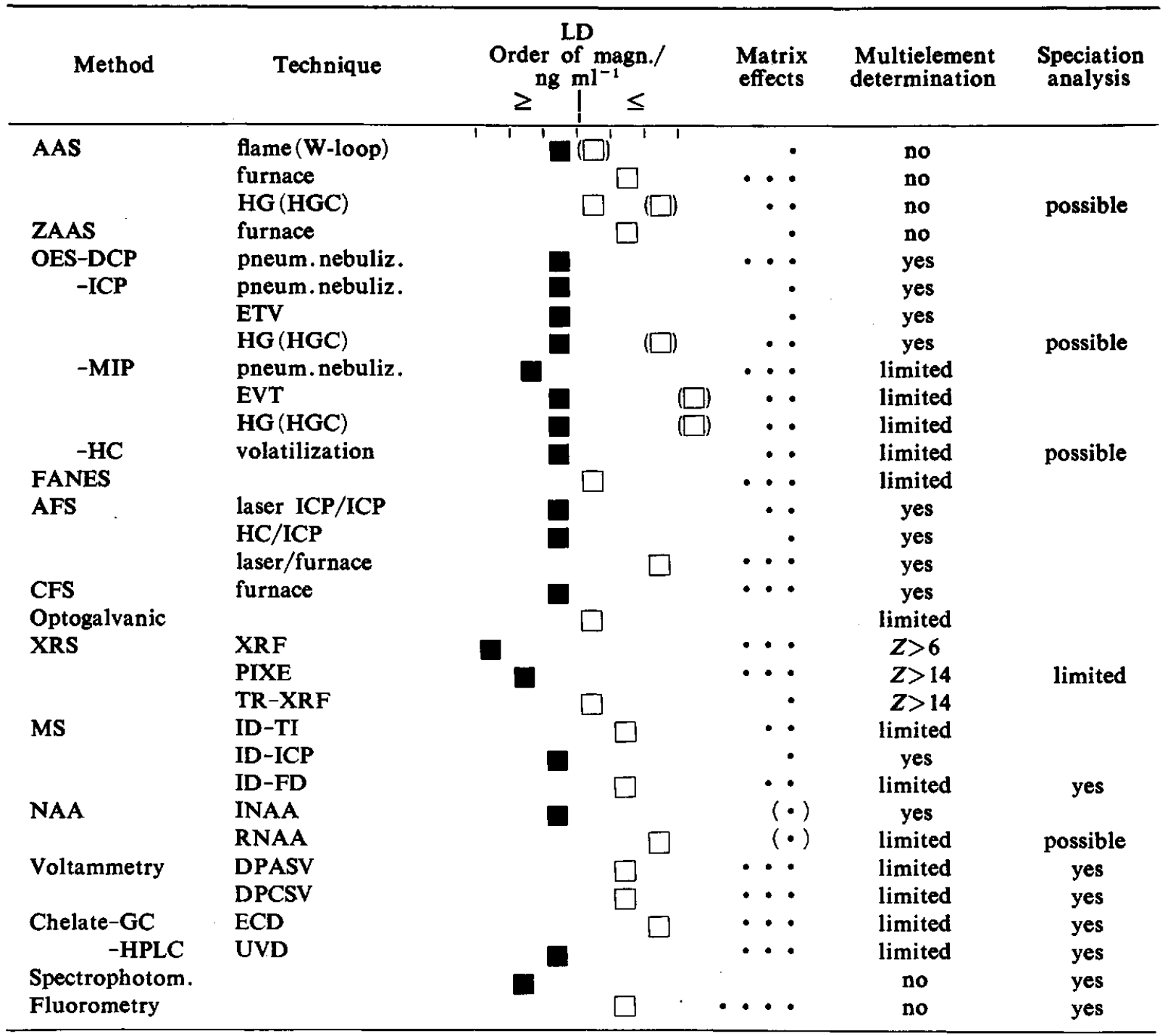

Black squares: for numerous elements; white squares: for special cases only. 
separation procedures should involve the least possible number of steps, a minimum of reagents and, wherever possible a sealed apparatus system with smallest possible surfaces. This can only be achieved with welladapted micro-techniques.

Separation in the gaseous phase (vaporization analysis) ${ }^{34}$, coprecipitation ${ }^{35}$ and precipitation exchange $^{37}$ as well as electrolytic methods ${ }^{38}$ are often to be preferred to liquid-liquid extraction and ionic exchange. ${ }^{10}$

For the determination of isolated elements or groups of elements there is a number of methods available, cf. Table $3 .^{39}$ In each case the most reliable way is to be chosen according to the problem at hand (element, power of detection, still present concomitant components a.o.). Usually, this last step of a combined procedure is less problematic. Initiated by still open analytical questions, an attempt is made in the following special section to discuss the general impressions given above at the hand of some examples more in detail.

\section{Special Section}

First example: The determination of $\mathrm{Hg}$ in the $\mathrm{pg} / \mathrm{g}$-region

This example was chosen because it permitted in almost ideal form the realization of a strategy in extreme trace analysis as discussed above.

For the study of antagonistic activities of $\mathrm{Hg}$ and $\mathrm{Se}$ in biological matrices, which involves analyses of the individual protein fraction of blood serum, the development of a determination method with extremly good power of detection and best reliability was required. Among the determination methods microwave-induced plasma optical emission spectrometry (MIP-OES) ${ }^{40}$ proved to be extremely sensitive and up

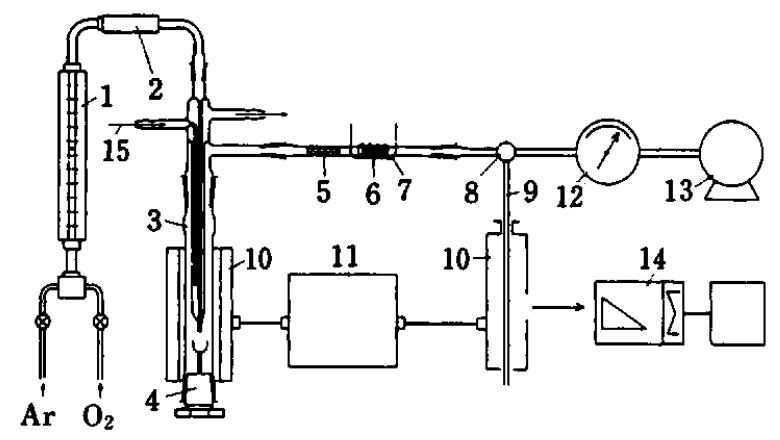

Fig. $7 \mathrm{Hg}$-determination by close combination of sample decomposition in microwave-induced oxygen, $\mathrm{Hg}$-preconcentration and determination again by MIP-OES.41 1) rotameter; 2) gas-purification; 3) quartz decomposition vessel; 4) sample holder; 5) quartz-wool; 6) gold absorber; 7) heating coil; 8) 3-way tap; 9) quartz-capillary; 10) microwave cavity; 11) microwave generator; 12) manometer, 13) vacuum pump; 14) spectrometer. to a large extend free of interferences. ${ }^{41}$

By its high volatility, $\mathrm{Hg}$ already can be separated from inorganic or organic matrices during the intitial decomposition stage in a sealed system by means of oxygen excited in a microwave field, $c f$. Fig. 7. The released $\mathrm{Hg}$ is then collected in an absorber tube and fixed on finely distributed gold. By a subsequent heating of the absorber, the released $\mathrm{Hg}$ is swept with argon into the microwave-induced plasma which results in a reliable detection of $\mathrm{Hg}$-amounts $\geqslant 1 \mathrm{pg}$. In this on-line combined procedure, systematic errors - mainly due to contamination - but also to $\mathrm{Hg}$ losses, are only encountered during sample preparation.

\section{Second example: The determination of Se in the $\mathrm{pg} / \mathrm{g}$ region}

While the determination of $\mathrm{Se}$ in organic matrices in principles is possible in the $\mathrm{ng} / \mathrm{g}$-region ${ }^{42}$, the power of detection of common methods is no longer sufficient for microtrace analyses, where micro-amounts of samples being in the lower $\mathrm{mg}$ or upper $\mu \mathrm{g}$-regions have to be analyzed. This occurs for instance, in the determination of the microdistribution of Se in microsections of tissue, biopsies or protein fractions of the blood serum. To overcome these problems, the only methods available up to now were the very powerful chelate-GC with ECD via piaz-selenol and the differential pulse cathodic stripping voltammetry (DPCSV). However, both are not free of interferences.

The power of detection of conventional hydride generation AAS is not sufficient. A more successful approach is shown in Fig. 8. In an initial step, the organic sample is decomposed in a Trace- $O$-Mat. ${ }^{43-45}$ During the combustion of the sample in a stream of pure oxygen in a small quartz cell, the $\mathrm{SeO}_{2}$ is volatilized and collected on a cooling finger (liquid nitrogen). After decomposition, Se together with only a few other volatile trace elements is dissolved within a few microliters of $\mathrm{HCl}$. The power of detection of the subsequent hydride-AAS is thereby decisively enhanced, because released $\mathrm{SeH}_{2}$ is collected in an absorber tube (Chromosorb) by cooling with liquid nitrogen. In the determination step $\mathrm{Se}$ is volatilized by a fast heating of the cooling trap. ${ }^{44}$

As a result of the $\mathrm{SeH}_{2}$ trapping, the limit of detection could be lowered to $5 \mathrm{pg} / \mathrm{g}$ without any loss of reliability. Interferences by other elements, which are usually difficult to eliminate, here simply can be circumvented. Indeed this combination of decomposition and a repeated separation of the Se allows a complete separation from non-volatile interfering elements (e.g. $\mathrm{Ni}, \mathrm{Cu})$. In the case of inorganic matrices, an auxiliary ashing agent such as high-purity cellulose has to be added to the sample.

This combination of methods even enables the determination of the natural Se-concentration within small fragments of a single hair. Accordingly it was possible to determine the Se-distribution along the entire length of one hair from root to end. ${ }^{44}$ However, 


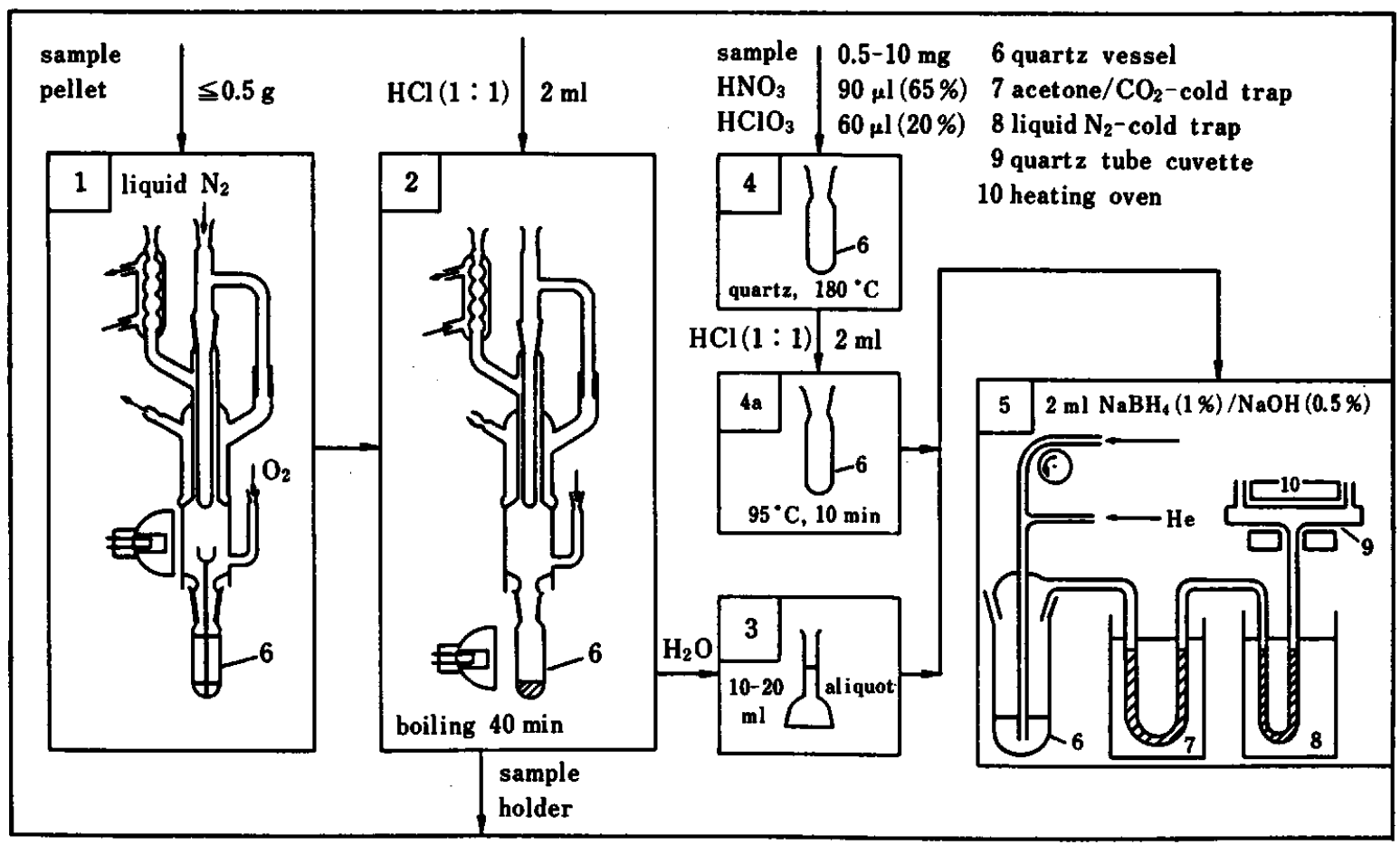

Fig. 8 Combined procedure for Se-determination in the $\mathrm{pg} / \mathrm{g}$-range after sample decomposition in a Trace-O-Mat and AAS-determination. ${ }^{44}$

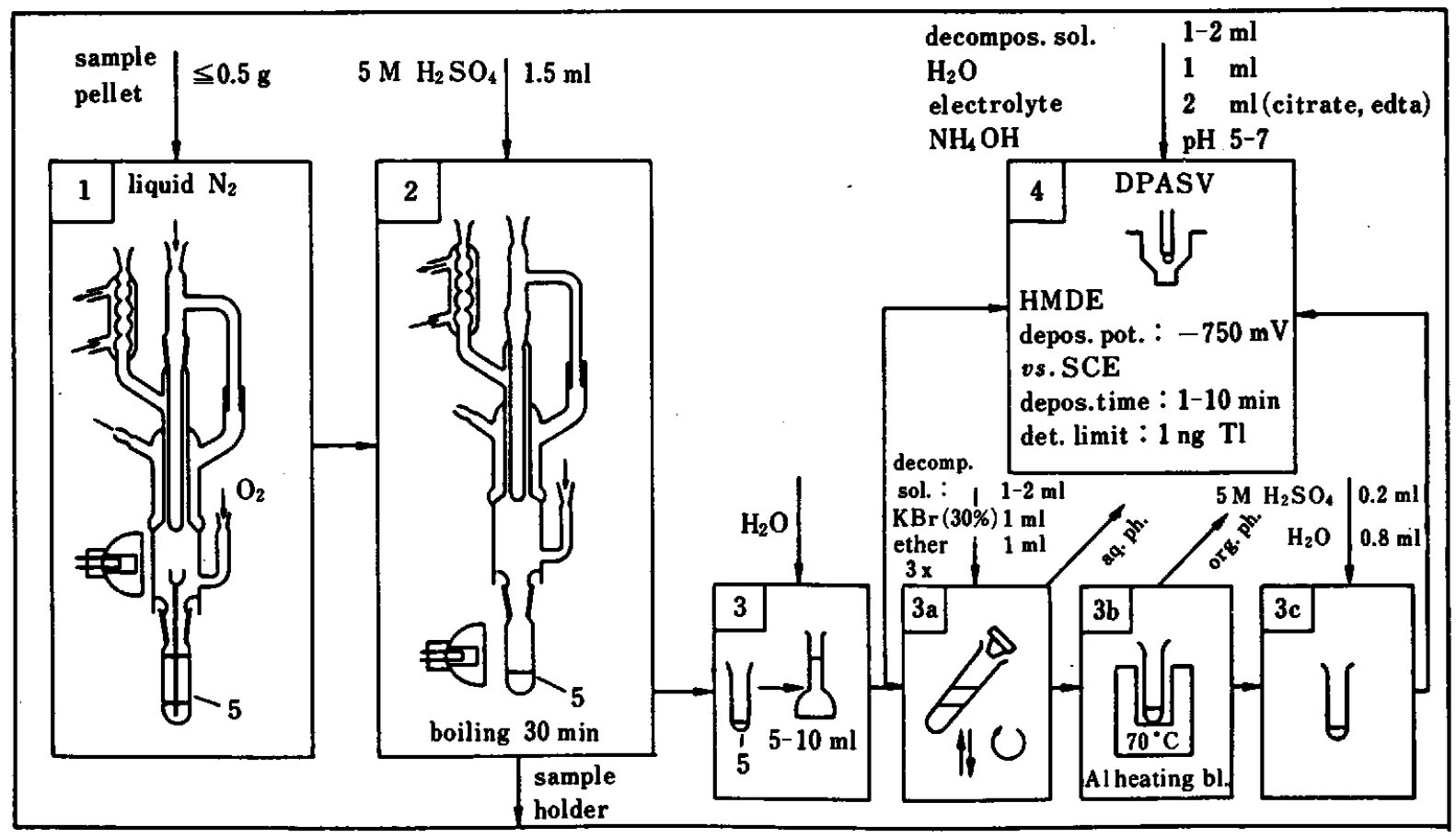

Fig. 9 Combined procedure for the determination of Tl-contents of $\geqslant 2 \mathrm{ng} / \mathrm{g}$ in inorganic and organic matrices by DPASV.47

the main aim of this investigation was the determination of the Se-distribution in the different protein fractions of the blood serum, so as to learn more about its essentiality and its potential of the protection against heavy metals $($ e.g. $\mathrm{Hg}, \mathrm{Cd}, \mathrm{Pb}) .{ }^{46}$
Third example: The determination of ultra-trace amounts of $T l$

The aim of our work on the determination of $\mathrm{Tl}$ was mainly to determine its micro-distribution in organic and biotic environmental samples. After extensive 
investigations the differential pulse anodic stripping voltammetry (DPASV) was found to be the electrochemical method of choice. ${ }^{45,46}$ In Fig. 9, the combined procedure is represented. The decomposition of inorganic and biotic samples - just as in the determination of $\mathrm{Se}-$ is performed in the Trace- $O$ Mat. Subsequently, the Tl is separated from the nonvolatile elements by vaporization. Only in a few special cases, a further separation step for $\mathrm{Tl}$ is necessary. It can be done by liquid-liquid extraction of the TI(III) bromide in diisopropyl ether, prior to its determination by DPASV. All operations for the isolation of $\mathrm{Tl}$ take place in the same quartz vessel. Organic samples can be burnt directly in pure oxygen by bringing them into the form of small pressed pellets $(\leqslant 0.5 \mathrm{~g})$. Inorganic samples (such as rocks, soils, cement) require the addition of powderized cellulose.

According to this principle, $\mathrm{Tl}$ concentrations $\geqslant 2$ $\mathrm{ng} / \mathrm{g}$ can be determined reliably in almost any inorganic and organic sample.

Fourth example: The determination of $P t$ and other noble metals in the $n g / g$ - and $p g / g$-region

Pt-catalysts in motor cars, as they get of use for reducing the $\mathrm{NO}_{x}$-content of the exhaust gases, throw up the question, whether or not in the future, $\mathrm{Pt}$ concentrations in the environment become so high that they cause new dangerous risks. If there is a such danger, it only can be expected over longer periods of time, as only relatively small amounts of $\mathrm{Pt}$ will be emitted. Reliable statements to this point, however, can only be made, if the present normal contents of $\mathrm{Pt}$ and the other Pt-metals in plants, animals and humans, which occur in the pg/g-region and partly even lower, can be determined reliably.

Many unexpected difficulties arose with respect to another sources of systematic error. The main problem is that it is not possible to store or handle solutions with very low ion concentrations of most of the Ptmetals. Very low concentrations of reducing contaminations introduced by the organic vessel material, by organic reagents, but also by dust-particles result in metal depositions on the vessel surfaces and thus in substantial negative systematic errors.

Accordingly, in the extreme trace analysis of the Ptmetals new approaches will have to be made in reducing these error sources, whereas here the problem of blanks is less important. The strategy to be followed can only be briefly commented here.

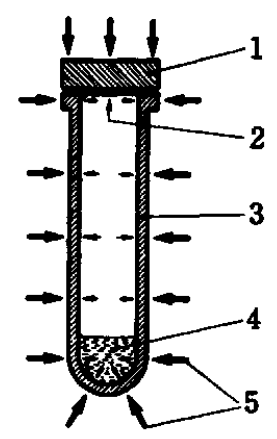

Fig. 10 Acid-decomposition in a quartz vessel under high pressure. (1) Cover of quartz, (2) inner pressure ( $\leqslant 100$ bar) (3) quartz vessel, (4) sample and $\mathrm{HNO}_{3},(5)$ outer pressure (100 bar). ${ }^{48}$

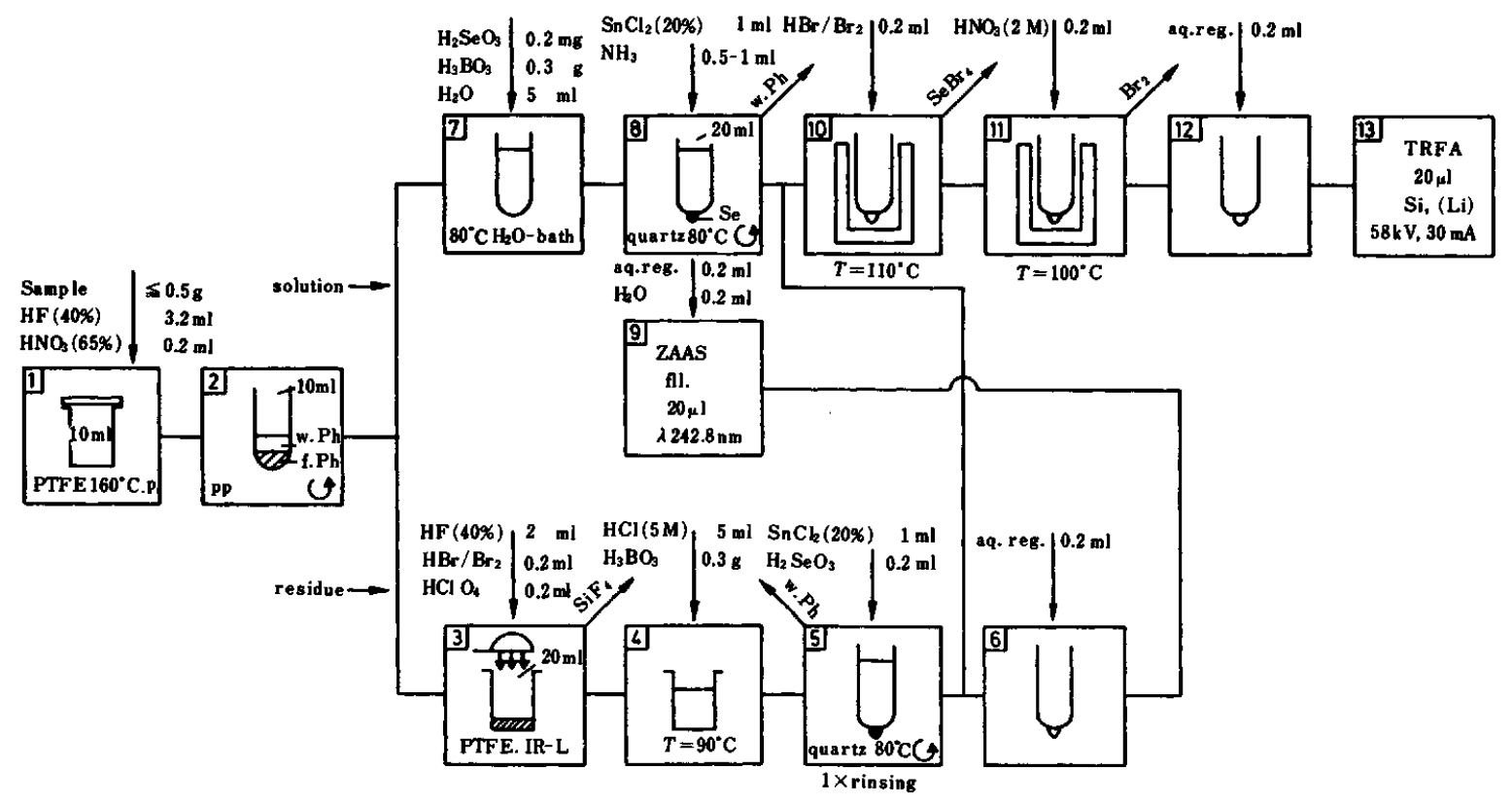

Fig. 11 Combined procedure for the determination of Au after sample decomposition; separation of Au-traces and their determination by ETAAS resp. by TRXRF. ${ }^{49}$ 
The decomposition with $\mathrm{HNO}_{3} / \mathrm{HCl}$ at temperatures $\geqslant 230^{\circ} \mathrm{C}$ in the pressure bomb is the most effective method for quantitative mineralization of the sample. A suitable decomposition device containing a quartz vessel, in which the high inner pressure is compensated by an outside counter pressure, $c f$. Fig. 10, was developed by Knapp.48

For the preconcentration of the Pt-traces, liquidliquid extraction as well as ion exchange techniques cannot be used. More favorable conditions are offered by the electrolytic deposition of the noble metals onto a very small cathode in a hydrodynamic system, but also by coprecipitation e.g. with Se. In order to determine the isolated $\mathrm{Pt}$, one has to use most sensitive determination methods such as NAA and TRXRF for simultaneous multielement determinations, or ZeemanAAS for individual element determinations. The development of such combined procedures now requires extensive investigations, assisted by radiotracers, if possible. Initial studies only showed what cannot be done, but nevertheless led to a conception of the powerful and reliable combined procedure for the Au-determination, summerized in Fig. 11.49

\section{Conclusion}

This contribution is intended to demonstrate once again the thorny path towards the achievement of reliable results in extreme trace analysis of the elements and the important role of the combined procedures. It would hardly be possible or might even prove dangerous to make any generalizing statements. In analyses at the $\mathrm{ng} / \mathrm{g}$-level, and even more at the $\mathrm{pg} / \mathrm{g}$ level combined procedures are indispensable. They can even be more economic than direct instrumental methods, as long as the latters are still hampered by lack of power of detection or systematic errors.

Therefore, progress in the extreme trace analysis less lies in the development of attractive spectrometers of all types involving "push-button-strategies", than in an endeavor to be self-critical and to exclude systematic errors, as well as to prevent oneself from becoming a victim of commercial "black-box-analysis".

We express our thanks to the Ministerium für Wissenschaft und Forschung des Landes Nordrhein-Westfalen and the Bundesminister für Forschung und Technologie for their support of our work.

\section{References}

1. G. Tölg and R. P. H. Garten, Angew. Chem. Int. Ed., Engl., 24, 485 (1985).

2. G. Tölg, Naturwiss., 63, 99 (1976).

3. G. Tölg, in "Fortschritte in der atomspektroskopischen Spurenanalytik", Vol. 1, pp. 5-21, ed. B. Welz, Verlag Chemie, Weinheim (1984).
4. G. Tölg, Mikrochim. Acta [Wien], 1981, 203.

5. M. Grasserbauer, Fresenius' Z. Anal. Chem., 324, 544 (1986).

6. M. Grasserbauer, Anal. Proc., 22, 287 (1985).

7. B. Griepink, Fresenius' Z. Anal. Chem., 317, 210 (1984).

8. K. Ohls and D. Sommer, Fresenius' Z. Anal. Chem., 312, 195 (1982).

9. G. Tölg, Erzmetall, 28, 390 (1975).

10. G. Tölg, Fresenius' Z. Anal. Chem., 294, 1 (1979).

11. P. Tschöpel, L. Kotz, W. Schulz, M. Veber and G. Tölg, Fresenius' Z. Anal. Chem., 302, 1 (1980).

12. K. Gretzinger, L. Kotz, P. Tschöpel and G. Tölg, Talanta, 29, 1011 (1982).

13. P. Tschöpel and G. Tölg, J. Trace and Microprobe Techn., 1, 1 (1982).

14. J. Versieck and R. Cornelis, Anal. Chim. Acta, 116, 217 (1980).

15. H. Berndt, J. Bassner and D. Sopczak, (ISAS, Dortmund, F. R. G.) publication in preparation.

16. G. Tölg, Pure Appl. Chem., 55, 1989 (1983).

17. A. von Bohlen, R. Eller, R. Klockenkämper and G. Tölg, Anal. Chem., to be published (1987).

18. P. Wobrauschek and H. Aiginger, Fresenius' Z. Anal. Chem., 324, 865 (1986).

19. E. C. Kuehner, R. Alvarez, P. J. Paulsen and T. J. Murphy, Anal. Chem. 44, 2050 (1972).

20. J. W. Mitchell, Talanta, 29, 993 (1982).

21. J. W. Mitchell, Anal. Chem., 50, 194 (1978).

22. J. R. Moody and E. S. Beary, Talanta, 29, 1003 (1982).

23. J. W. Mitchell, Anal. Chem., 45, 492A (1973).

24. J. R. Moody, Anal. Chem., 54, 1358A (1982).

25. S. B. Adeloju and A. M. Bond, Anal. Chem., 57, 8 (1985).

26. L. Mart, Talanta, 29, 1035 (1982).

27. D. Schmidt, Fresenius' Z. Anal. Chem., 316, 566 (1983).

28. C. Boutron, Anal. Chim. Acta, 106, 127 (1979).

29. G. Knapp, Fresenius' Z. Anal. Chem., 317, 213 (1984).

30. R. Bock in "Analytiker Taschenbuch", S. 19, ed. H. Kienitz, R. Bock, W. Fresenius, W. Huber, G. Tölg, Springer Verlag, Berlin, Heidelberg, New York (1980).

31. R. Bock, "A Handbook of Decomposition Methods in Analytical Chemistry", Internat. Textbook Co., Ltd., London (1979).

32. G. Tölg, Talanta, 19, 1489 (1972).

33. A. Mizuike in "Enrichment Techniques for Inorganic Trace Analysis", Springer Verlag, Berlin, Heidelberg, New York (1983).

34. K. Bächmann, CRC Critical Rev. in Anal. Chem., 12, Issue 1 (1981).

35. A. Mizuike, Fresenius' Z. Anal. Chem., 324, 672 (1986).

36. R. Van Grieken, Anal. Chim. Acta, 143, 3 (1982).

37. A. Disam, P. Tschöpel and G. Tölg, Fresenius' Z. Anal. Chem., 295, 97 (1979).

38. M. Hiraide, P. Tschöpel and G. Tölg, Anal. Chim. Acta, 186, 261 (1986).

39. G. Tölg, Analyst [London], in press.

40. D. Kollotzek, P. Tschöpel and G. Tölg, Spectrochim. Acta, 39B, 625 (1984).

41. G. Kaiser, D. Götz, G. Tölg, G. Knapp, B. Maichin and H. Spitzy, Fresenius' Z. Anal. Chem., 291, 278 (1978).

42. S. E. Raptis, G. Kaiser and G. Tölg, Fresenius' Z. Anal. Chem., 316, 105 (1983).

43. H.-B. Han, G. Kaiser and G. Tölg, Anal. Chim. Acta, 128, $9(1981)$.

44. J. Piwonka, G. Kaiser and G. Tölg, Fresenius' Z. Anal. 
Chem., 321, 225 (1985).

45. G. Kaiser and G. Tölg, Fresenius' Z. Anal. Chem., 325, 32 (1986).

46. F. Alt, J. Messerschmidt, G. Tölg, G. Kaiser and J. Piwonka, Fresenius' Z. Anal. Chem., 317, 658 (1984).

47. I. Liem, G. Kaiser, M. Sager and G. Tölg, Anal. Chim.
Acta, 158, 179 (1984).

48. G. Knapp, Aerzt. Lab., 28, 179 (1982).

49. R. Eller, Dissertation, Universität Mainz (1986).

(Received April 10, 1987)

(Accepted April 20, 1987) 